\title{
Combined Optical and TEM Investigations for a Detailed Characterization of Soot Aggregate Properties in a Laminar Coflow Diffusion Flame
}

Nathan Kempema*, Marshall Long

Department of Mechanical Engineering and Materials Science, Yale University, 15 Prospect St., New

Haven, Connecticut 06511, USA

*Corresponding Author. Email Address: nathan.kempema@yale.edu (920-723-7557)

\begin{abstract}
In order to develop soot models that include effects due to particle aggregation, data must be obtained from flames containing all of the relevant chemical and physical processes that affect the evolution of a soot particle. In this study, the effective radius of gyration of aggregated soot is experimentally determined in nitrogen-diluted ethylene coflow diffusion flames using 2-D multi-angle light scattering (2D-MALS). High spatial resolution is achieved by minimizing signal blur that results from imaging light scattering from the probe volume at oblique angles. The results are validated at six locations in the flame through comparison to an effective radius of gyration derived from transmission electron microscope (TEM) analysis of thermophoretically-sampled soot. Simulations are used to model the path taken by a soot particle to reach the TEM grid to ensure the sampling measurements have the spatial resolution necessary to differentiate between aggregate properties at different radial locations in the flame. A radial distance $\delta$ is determined from which the front face of the probe is offset from the desired sample location. The ability of the probe to separately capture wing and centerline soot morphology is confirmed by comparison to a previous timeresolved laser-induced incandescence (TiRe-LII) measurement of primary particle diameter. The observed increase in polydispersity and maximum diameter of primary particles along the flame wing compared to the centerline is thought to be a result of surface growth. Excellent agreement is found between the effective radius of gyration derived from 2D-MALS and TEM analysis. The TEM results not only confirm the optical measurement but also elucidate the effective radius of gyration, which depends on aggregate size and polydispersity.
\end{abstract}

Keywords: Laminar coflow diffusion flame, soot aggregate, TEM, elastic light scattering

\section{Introduction}

As a result of incomplete combustion, soot particles enter the atmosphere where they can have complex negative impacts on the environment and human health. Recent studies have shown soot to have potentially carcinogenic and mutagenic effects due to biologically active components such as polycyclic aromatic hydrocarbons $[1,2]$. As an aerosol, soot impacts the environment through its global transport and deposition on the polar ice caps, thus changing the surface optical properties and increasing light absorption [3]. The optical properties and toxicity of soot depend on particle morphology, thus providing a need for the development of a complete model of soot formation and oxidation.

A coflow diffusion flame provides a multidimensional and computationally tractable environment for the study of soot formation with detailed chemistry. The Yale coflow burner was selected for this study since several different flame conditions stabilized on this burner have been investigated previously [4-11] and one is a target flame for the international sooting flames workshop [12]. Prior soot modeling in this burner utilized a sectional approach in which the soot particles are treated as isolated spheroids, divided into sections or classes based on size, that coalesce upon collision. The assumption of spherical particles that coalesce upon impact is consistent with our understanding of young soot, which has been shown to have a sphere-like shape and liquid-like behavior [13]. However, mature soot is described as a fractal aggregate comprised of nearly spherical carbonized primary particles. The primary particles reach a maximum size and grow very little after a certain point in the evolution of the particle, at which point the dominant mode of particle growth is agglomeration. The fractal concept is important compared to a spherical approximation because it increases the aggregate surface area, thus affecting surface growth and oxidation processes. In order to provide a more accurate comparison to experimental data, aggregate soot models, such as in Ref. [14], must be utilized to capture the fractal nature of soot aggregates. As will be shown, multidimensional data in coflow flames can capture differences in morphology between particles with different temperature-time histories, which can be useful for the development and validation of soot aggregation models. 
Elastic light scattering from soot aggregates, understood through the Rayleigh-Debye-Gans approximation for fractal aggregates (RDG-FA), is useful for nonintrusive in situ measurement of aggregate morphology and has been used extensively for point measurements in laminar and turbulent flames [15]. One and two-angle elastic light scattering are often used in conjunction with laser-induced incandescence (LII) to measure soot morphology $[16,17]$. However, these techniques require additional information such as the ratio of the soot scattering to absorption functions and/or information about the aggregate size distribution in order to provide a measure of aggregate size. Wide-angle light scattering was developed to simultaneously collect scattered light over a range of angles using a single detector and has been successfully applied in premixed laminar and turbulent diffusion flames, although it is limited to point measurements $[18,19]$. Various other elastic scattering techniques have been developed for in situ point measurement from a polydisperse distribution of soot aggregates [20-22]. However, using a point measurement technique to obtain multidimensional data increases the experimental complexity and data acquisition time. Two-dimensional measurements of aggregate size can be derived from one-angle elastic light scattering when combined with LII [23, 24]. Ma and Long [5] applied 2-D multi-angle light scattering (2D-MALS) in the Guinier limit [15] to determine an effective radius of gyration in a laminar coflow diffusion flame. That measurement was combined with a spectrally resolved line-of-sight extinction technique and primary particle data from a time-resolved laser-induced incandescence (TiRe-LII) measurement to map the soot dispersion exponent in two-dimensions. However, the spatial resolution of the measured effective radius of gyration was limited due to signal smear [5]. This work will improve the spatial resolution of 2D-MALS in a coflow flame and provide validation to the optical measurement through an ex situ analysis of sampled soot aggregates [19,25].

In 1987, Dobbins and Megaridis first demonstrated the value of ex situ analysis to determine aggregate morphology using a transmission electron microscope (TEM) and thermophoretic sampling [26]. Analysis has since been extended through the use of scanning electron, atomic force, and helium-ion microscopes to visualize and capture particle morphology [13, 27]. Soot particles are extracted from the flame for analysis using a probe that generates a local temperature gradient. Particles within the probe's thermal boundary layer experience a force in the direction of the negative temperature gradient due to the nonhomogeneous kinetic energy of gas-phase molecules in the direction of the temperature gradient. Since the first use of thermophoretic sampling, various probe designs have been utilized to extract particles [28]. However, very little work has been done to quantify the spatial resolution of such probes, which would be useful for sampling multidimensional flames. In one paper, Lee et al. used vibration analysis and highspeed imaging to predict and quantify the vibrational mode and frequency of a probe having undergone a rapid insertion [28]. They demonstrated through combined schlieren/shadowgraph imaging that the perturbation to the flow field of a flat premixed flame was significant, and that probe geometry could affect sampling results due to excessive vibration. After adding snubbers that dampen vibration by regulating air flow to the pneumatic cylinder and optimizing the probe cross sectional area, they were able to resolve growth of silica aggregates with increasing height above burner (HAB) in a flat premixed flame. Vibrational analysis is sufficient to achieve the spatial resolution necessary to resolve growth in a flat flame burner, where aggregate morphology changes only in the axial direction. However, coflow flames feature two-dimensional flow fields in which soot aggregate properties vary in the axial and radial directions. In order to effectively sample multidimensional flames, understanding of the sampling process must be expanded beyond vibrational analysis to consider the thermal boundary layer that forms around the probe and how it influences the path of a particle to the TEM grid.

The work presented here will focus on the growth and morphology of fully carbonized soot aggregates in two-dimensions on the Yale coflow burner [29]. The flow conditions are set by flowing ethylene diluted with nitrogen to $40 \%, 60 \%$, and $80 \%$ of the total volume flow rate through the fuel tube, thereby providing flames of different characteristic length and soot loading. The spatial resolution in the measured soot effective radius of gyration will be improved over a previous measurement [5] by minimizing data smear that occurs at oblique light collection angles. Thermophoretic sampling will then be used to validate the optical measurement by deriving effective radius of gyration from an ex situ analysis. In order to achieve the radial resolution necessary to compare with 2D-MALS data, velocity and temperature fields around the sample probe will be modeled to predict the path along which an aggregate travels to reach the TEM grid. In their original work, Dobbins and Megaridis estimated the boundary layer thickness through heat transfer analysis [26]. In this work, we will extend that analysis by modeling the real probe geometry and path taken by an aggregate to reach the TEM grid. The simulations suggest a simple and less invasive method for sampling the flame wing compared to a direct insertion of the probe into the 
sample location. The wing is considered to be the region of maximum soot volume fraction that exists inside the high temperature reaction zone in the $80 \%$ flame [4,5]. Spatial resolution will be demonstrated by measuring the primary particle diameter of aggregates sampled along the wing and centerline of a flame, where previous TiRe-LII data indicates a difference in maximum size and polydispersity [7]. Samples were taken at several locations in the flame in order to calculate discrete probability density functions $(p d f s)$ for the number of primary particles per aggregate and radius of gyration. This data will then be used to calculate an effective radius of gyration and validate the 2D optical measurement. The TEM-derived morphological parameters are relevant to the optical properties of soot and therefore have implications for the measurement of soot temperature using color-ratio pyrometry. The wavelength dependence of soot emissivity and can be calculated with knowledge of particle morphology and polydispersity [5]. A previous measurement of soot temperature will be updated in the supplementary material to include the highresolution measurement of effective soot radius of gyration and information about aggregate morphology.

\section{Multi-angle light scattering}

\subsection{RDG-FA theory}

Soot aggregates are characterized as mass fractals that obey a power-law scaling dependence according to Eq. (1)

$$
N=k_{0}\left(\frac{2 R_{g}}{d_{p}}\right)^{D_{f}},
$$

where $N$ is the number of primary particles per aggregate, $k_{0}$ is the fractal prefactor, $R_{g}$ is the radius of gyration, $d_{p}$ is the primary particle diameter, and $D_{f}$ is the fractal dimension. In order to optically interrogate the morphology of a distribution of soot particles, the Rayleigh-Debye-Gans approximation for fractal aggregates is used to model light scattering. Interpreting the scattering process through this theory is suggested to be accurate within $10 \%[15,30]$.

Fig. 1. Representation of light scattering from a simulated soot aggregate.

Figure 1 illustrates scattering from a simulated soot aggregate [31]. An incident wave vector $K_{i}$ is scattered in a direction $\theta$, producing a wave vector $K_{s}$, the difference of which yields a third vector denoted as the scattering wave vector $q$. The inverse of the resulting scattering wave vector is useful as it provides a length scale that can be used to probe aggregate morphology [15]. The illumination wavelength and detection angle determine the scattering wave vector according to its definition $q=4 \pi \lambda^{-1} \sin (\theta / 2)$, where $\lambda$ is the laser wavelength and $\theta$ is the scattering collection angle relative to the forward direction of the optical path. Experiments with $q^{-1}<d_{p}$ are used to determine the primary particle diameter, whereas $d_{p}<q^{-1}$ $<R_{g}$ determines the fractal dimension, and $R_{g}<q^{-1}$ measures the aggregate radius of gyration. The last case, also known as the Guinier regime, will be used here to measure an effective radius of gyration.

Under RDG-FA, all of the primary particles scatter independently, resulting in a scattered intensity defined by the following equation:

$$
I_{s c a}(q)=I_{0} n N^{2} V \frac{d \sigma^{p}}{d \Omega} S\left(q R_{g}\right)
$$

where the incident laser intensity is $I_{0}, n$ is the aggregate number density, $N$ is the number of monomers per aggregate, $V$ is the probe volume, $\frac{d \sigma^{p}}{d \Omega}$ is the scattering cross section of a monomer, and $S\left(q R_{g}\right)$ is the structure factor that accounts for the angular dependence of the scattered intensity. A Guinier regime analysis utilizes the set of data obtained by taking the ratio of signal collected at $0^{\circ}$ with that from all other collection angles. In practice, data obtained at $10^{\circ}$ is substituted for $0^{\circ}$ in order separate the scattered signal from the transmitted laser sheet. The ratio of signals acquired at different angles cancels all of the terms in Eq. (2) except the structure factor and angular dependence of $V$. This allows for the effective radius of 
gyration to be determined from a linear fitting of the signal ratios plotted against the square of the scattering wave vector as in Eq. (3)

$$
\frac{I_{\text {sca }}\left(q\left(\lambda, 10^{\circ}\right)\right)}{I_{\text {sca }}(q(\lambda, \theta))} \approx 1+\frac{1}{3} q(\lambda, \theta)^{2} R_{g, e f f}^{2}, \quad R_{g, e f f}^{2}=\frac{\int N^{2} R_{g}^{2}(N) n(N) d N}{\int N^{2} n(N) d N}=\left(\frac{d_{p}}{2}\right)^{2} k_{0}^{-\frac{2}{D_{f}}} \frac{M_{2+2 / D_{f}}}{M_{2}}
$$

where $R_{g}(N)$ and $n(N)$ are the radius of gyration and aggregate number density distributions. Typically, Guinier regime analysis is limited to $I_{\text {sca }}\left(q\left(\lambda, 10^{\circ}\right)\right) / I_{\text {sca }}(q(\lambda, \theta))<2$ [15]. In this study, however, ratios up to 3 were used to increase the number of data points, since using the larger value made little difference in the $R_{g, e f f}$ determined through fitting. The radius of gyration is termed "effective", since aggregates are polydisperse and the measurement is sensitive to higher moments $(>1)$ of the size distribution. The $i^{\text {th }}$ moment $\left(M_{i}\right)$ of the distribution is defined according to Eq. (4).

$$
M_{i}=\int_{N=1}^{N=\infty} n(N) N^{i} d N
$$

The proportionality of the effective radius of gyration to higher moments of the distribution biases the measurement toward aggregates larger than the arithmetic mean. However, this parameter can be validated against sampled soot aggregates and could be computed from the results of a computational model.

\subsection{Experiment}

The experimental configuration for the 2D-MALS measurements is shown schematically in Fig. 2. The Yale burner features a $4 \mathrm{~mm}$ I.D. fuel tube concentric with a $74 \mathrm{~mm}$ I.D. coflow of air exiting a honeycomb mesh with $0.8 \mathrm{~mm}$ cells. The average fuel-tube exit velocity (parabolic velocity profile) and coflow exit velocity (plug velocity profile) were matched at $35 \mathrm{~cm} / \mathrm{s}$. The illumination source was the second harmonic of an Nd:YAG laser (Spectra Physics Quanta-Ray Pro, $10 \mathrm{~Hz}$ ) reflected from the front face of a $10^{\circ}$ optical wedge in order to reduce the laser pulse energy. The primary beam transmitted through the wedge along with an additional reflection from the back face of the optical wedge were removed with beam dumps. The illumination beam was then expanded by a factor of four in a direction normal to the optical table through a $25 \mathrm{~mm}$ plano-concave cylindrical lens and a $100 \mathrm{~mm}$ plano-convex cylindrical lens. A neutral density filter was used to reduce the laser fluence below $0.2 \mathrm{~J} / \mathrm{cm}^{2}$ in order to prevent morphological changes to the soot as a result of laser heating [32-34]. The laser beam was then cut to a height of $1.2 \mathrm{~cm}$ with razor blades and focused above the burner with a $200 \mathrm{~mm}$ focal length plano-convex cylindrical lens. To determine the sheet thickness, a CCD camera (GigE GC1380CH without lenses, $1024 \mathrm{x}$ 1360 pixels, $6.45 \mu \mathrm{m}$ square pixels) was placed into the laser sheet, which was attenuated with ND filters. The detector was translated on a stage and the sheet thickness was measured to be $16 \mu \mathrm{m}$ at the focal point and $163 \mu \mathrm{m}$ at a distance $2 \mathrm{~mm}$ from the focal point. Average laser energy at each measurement location was recorded using a pyroelectric power meter (LaserProbe RjP-734), which also acted as a beam stop. Image data was normalized to account for fluctuations and drift in the laser energy. The detector was a monochrome version of the detector used for the sheet thickness measurements and the signal was collected at each angle $\left(10-90^{\circ}\right.$ in $10^{\circ}$ increments) through a $532 \mathrm{~nm}$ interference filter (full width half max of 10 $\mathrm{nm}$ ) using a $200 \mathrm{~mm}$ Vivitar lens and $\sim 11.5 \mathrm{~cm}$ extension tube. This resulted in an area of $\sim 7 \mathrm{x} 7 \mu \mathrm{m}^{2}$ at $90^{\circ}$ and $\sim 46 \times 7 \mu \mathrm{m}^{2}$ at $10^{\circ}$ projecting onto each pixel in the image plane. The aperture was set to $\mathrm{f} / 22$ in order to achieve a depth of field greater than the maximum flame diameter, which was verified by imaging a target centered on the fuel tube at $\theta=10^{\circ}$. The distance between the camera and burner was fixed with a rod attached to the camera assembly that was attached to a ring, which was co-annular with the burner. The burner top and co-annular ring were fitted with angular targets to align the camera at a particular viewing angle. The burner was translated vertically with a programmable stepper motor and images were tiled in 7 $\mathrm{mm}$ increments. Only the half of the flame on which the laser beam was focused was imaged due to the cylindrical symmetry of the flow. At each measurement location, 200 images were acquired and averaged in order to increase the signal-to-noise ratio and average out small fluctuations in the flame position. Flame luminosity was negligible due to the narrowband interference filter and short $10 \mu$ s exposure. Even though the contribution from spurious scattering in the experiment was small, 50 background images were 
acquired with the flame off and laser on and subtracted from the average signal image. Additional images were acquired with the $532 \mathrm{~nm}$ interference filter replaced by a $430 \mathrm{~nm}$ interference filter (full width half max of $10 \mathrm{~nm}$ ) to verify that no laser-induced incandescence signal was collected. The stepper-motor, power-meter, and camera were synchronized and controlled with the open source software OMA [35].

Fig. 2. Experimental 2D-MALS configuration.

\subsection{Data Processing}

A primary concern when using 2D-MALS is the loss of spatial resolution that occurs when imaging scattering from the probe volume at oblique angles. There are two ways in which resolution is lost. The first is analogous to the projection of a 2D plane at an oblique angle, where the length projected onto a pixel (in 1D) increases by a factor of $[\sin (90 \square) / \sin (\theta)]$ when collecting light at an angle $\theta$ compared to $90 \square$. This effect is fixed for a given collection angle. The second contribution to loss of resolution is blurring, which is not only a function of the collection angle but also the probe volume thickness. Blurring occurs when signal at the same radial location in the flame but at different thicknesses in the probe volume is imaged onto different pixels at the detector [5]. This effect is minimized when the probe volume thickness is at a minimum. In the current experiments, the focal point was fixed at the radial location of the wing at half the flame height, where radial spatial gradients are largest. Thus, blurring was minimized in the region of the flame where the greatest spatial resolution is required.

Spatial matching of images acquired at various viewing angles was achieved through bilinear warping and information derived from target images acquired at each angle. Images from angles $>10^{\circ}$ were blurred to match the minimum resolution image, which occurs at $10^{\circ}$ as explained in Ref. [5].

\section{Thermophoretic sampling}

\subsection{Sampler design}

A pneumatic sampler was constructed based on the design of Herdman et al. [36]. A $2.54 \mathrm{~cm}$ construction cube (ThorLabs RM1G) was used to attach the sampler tongue to the front of a pneumatically driven sliding rail (Omega DLM-09M-50-50-P). The tongue, used to hold the TEM grid during sampling, was constructed from $381 \mu \mathrm{m}$ thick stainless steel and is depicted in Fig. 3. The grid was placed at the end of the tongue, which was $4 \mathrm{~mm}$ tall in order to accommodate the $3 \mathrm{~mm}$ diameter TEM grid. A stainless steel washer ( $4 \mathrm{~mm}$ tall and $254 \mu \mathrm{m}$ thick with a $1 \mathrm{~mm}$ diameter hole) was placed over the TEM grid and glued to the surface of the tongue with a very small amount of epoxy. The hole exposed the center portion of the grid during sampling. The tongue features a square backside to maximize contact with the construction cube and minimize vibration. The tongue was inserted into the flame through a $50.8 \times 3.175$ $\mathrm{mm}^{2}$ slot, milled through a piece of acrylic, in order to block perturbations to the flow field as a result of the sliding rail's motion. The rail was driven a travel distance of $5 \mathrm{~cm}$ by compressed air through a series of solenoid valves (Omega SV3110). The solenoid valves were operated by two solid-state relays (Omega SSR330DC10) that were controlled by a low voltage circuit comprised of two delay generators and a LabJack U3-HV DAQ device controlled with OMA [35]. Lengthening or shortening the pulse length on the delay generators adjusted the sample time. Insertion and extraction times were characterized by imaging the tongue at $5 \mathrm{kHz}$ using a Vision Research Phantom v7.3 detector. The average travel time for insertion and extraction was $7.5 \mathrm{~ms}$. A GigE GC1380CH detector was used to image radial vibration of the probe after the insertion process as in Ref. [28]. Since the estimated natural frequency of a similar sample probe is much higher than the camera acquisition rate $(150 \mathrm{~Hz})$ [28], 200 image sequences were taken with a random phase relationship between the start of image acquisition and the start of probe motion. The maximum total radial displacement of the probe due to vibration was observed to be $<400 \mu \mathrm{m}$ and the maximum total displacement in the axial direction was observed to be $<300 \mu \mathrm{m}$. Sample times varied from $80-170 \mathrm{~ms}$, depending on the local soot volume fraction, in order to avoid overlap of aggregates on the sample grid as will be discussed in Section 4.3. The sample tongue was scrubbed with water and allowed to dry after each sample in order to avoid cross-contamination between sample locations. 
Fig. 3. Cut-away end and side views of the sample probe.

\subsection{Sampling simulations}

Two-dimensional simulations of the flow field around the sample probe were conducted using SOLIDWORKS software. A transient analysis was conducted to capture the growth of the thermal boundary layer around the probe, while ignoring perturbations to the flow field due to insertion and extraction of the probe. As a first approximation, the flame was modeled as a non-reacting uniform flow of nitrogen with a temperature of $1700 \mathrm{~K}$ and an axial velocity that varied from $0.35-2 \mathrm{~m} / \mathrm{s}$. These values were chosen based on information from previous experimental and computational studies $[4,5,10]$. Nitrogen properties were used since computational results for the $80 \%$ flame indicate that the mole fraction of $\mathrm{N}_{2}$ is greater than 0.6 at all measurement locations. The probe dimensions were selected to match a cross section of the actual probe geometry located at the center of the sampling hole. Heat transfer to the probe was modeled using a thermal conductivity of $16 \mathrm{~W} /(\mathrm{m} \cdot \mathrm{K})$ and a specific heat of $500 \mathrm{~J} /(\mathrm{kg} \cdot \mathrm{K})$ for stainless steel. The simulations modeled a $100 \mathrm{~ms}$ sample at $5 \mathrm{~ms}$ time intervals. A non-uniform mesh with radial and axial domains of $-7 \leq r \leq 7 \mathrm{~cm}$ and $-2 \leq z \leq 2 \mathrm{~cm}$ was used as the solution grid. Solutions were computed on grids of different extent to ensure that the result was independent of the computational domain. In addition, the mesh and time intervals were refined to ensure that the final solution was not a function of the spatial and temporal discretization.

The axial and radial fluid velocity fields along with the fluid and probe temperatures were exported and processed in MATLAB. Data from the non-uniform solution grid was bilinearly interpolated onto a uniform $10 \mu \mathrm{m}$ grid. At each time interval in the solution, particle motion was simulated starting from each point on the TEM grid surface and calculating motion backward in time. The particle location was calculated on a sub-grid scale at $0.1 \mathrm{~ms}$ time intervals and the local velocity vectors were interpolated from the $10 \mu \mathrm{m}$ solution grid.

The particles were assumed to behave in the limit of $S t k<<1$, where $S t k$ is the Stokes number. In this case, particles follow the local velocity vector of the flow unless a temperature gradient is present, in which case the vector sum of the induced thermophoretic velocity and the local fluid velocity determines the net particle velocity vector. The thermophoretic velocity vector is defined in Eq. (5)

$$
\overrightarrow{V_{T}}=-K v \frac{\nabla \mathrm{T}}{T},
$$

where $K$ is the thermophoretic velocity coefficient $(K \approx 0.55$ in the free molecular regime), $v$ is the kinematic viscosity of the host gas, and $T$ is the temperature [26, 37]. For spherical particles, the thermophoretic velocity is constant over a range of sizes that depends on the Knudsen number, $K n=l_{g} / l_{p}$, where $l_{g}$ is the gas mean free path and $l_{p}$ is the particle diameter. In order for the velocity given by Eq. (5) to be independent of particle size, the condition $K n>0.7$ must be satisfied [38]; for nitrogen at $1000 \mathrm{~K}$ (approximate mean gas temperature over the thermal boundary layer), this yields a maximum particle diameter of $\sim 450 \mathrm{~nm}$. Soot aggregates are not spheres, but it was shown by Rosner et al. [39] that the thermophoretic diffusivity $(K v)$ of a soot aggregate is within $8 \%$ and $21 \%$ of that an isolated spherical primary particle of the aggregate in the free molecular and continuum regimes, respectively. In Section 4.2, we will show that the primary particle diameter of the soot aggregates is well within the $\sim 450 \mathrm{~nm}$ diameter limit. Therefore, large aggregates in the sample are assumed to be collected at the same rate as smaller aggregates down to a minimum size. The smallest diameter particle that exhibits constant thermophoretic velocity is estimated as the minimum quantity to satisfy Eq. (6) [40, 41].

$$
m_{p} l_{p}^{3}>(8 \pi \sqrt{2}) m_{g} d_{g}^{2} l_{g}
$$

The soot particle mass is given by $m_{p}$, and the gas molecule mass and effective diameter are given by $m_{g}$ and $d_{g}$, respectively. For nitrogen at $1000 \mathrm{~K}$ and a soot density of $1.8 \mathrm{~g} / \mathrm{cm}^{3}$ [42], the minimum particle diameter is $\sim 2 \mathrm{~nm}$. This value is approximately four standard deviations below the mean monomer size of 
soot aggregates in a similar ethylene coflow diffusion flame and is therefore inconsequential to the measurement [43]. As a result, we expect the thermophoretic velocity to be approximately constant for all particle sizes in the flame and for the sampled aggregates to be representative of the number density of aggregate sizes within the flame.

Fig. 4. Thermophoretic sampling simulations with grid offsets of $254 \mu \mathrm{m}(u=0.35 \mathrm{~m} / \mathrm{s}$, left $), 254 \mu \mathrm{m}$ $(u=2 \mathrm{~m} / \mathrm{s}$, center $)$, and $0 \mu \mathrm{m}(u=2 \mathrm{~m} / \mathrm{s}$, right $)$.

Figure 4 illustrates the origin of particles that reach the TEM grid surface at different sample times. The black structure is the simulated sample probe cross section with an offset determined by the thickness of the washer used to adhere the TEM grid to the probe surface. The colored dots depict particles that reach the grid in an amount of time corresponding to the value on the color bar. Images are not presented to scale in order to include upstream particles in the figure. The particle streaks have the same general shape, where upstream particles are initially driven away from the grid surface as the flow is forced around the probe until the thermophoretic velocity is dominant and drives the particles to the TEM grid. A length $\delta$ is defined as the distance between the front surface of the probe and the radial location of upstream particles that reach the grid surface. To calculate $\delta$, the radial location of the front face of the sample probe is subtracted from the mean radial position of particles that have been tracked backward in time from the face of the TEM grid to an upstream location at which their radial velocity is negligible (ie. at an axial location where the particle velocity has not been affected by the presence of the probe). The length $\delta$ is a function of the local axial velocity (for a fixed fluid temperature) and varies from large positive values at small axial velocities to slightly negative values at high axial velocities. For a relatively slow flow $(u=0.35$ $\mathrm{m} / \mathrm{s}$ ) at $1700 \mathrm{~K}, \delta$ is $\sim 290 \mu \mathrm{m}$ (Fig. 4, left). For $u=2 \mathrm{~m} / \mathrm{s}, \delta$ was found to be $\sim-70 \mu \mathrm{m}$ and is independent of the offset between the front surface of the probe and the TEM grid for a given flow velocity and temperature (Fig. 4, center and right). The simulations were also conducted with a flow velocity of $1 \mathrm{~m} / \mathrm{s}$ and temperature of $1700 \mathrm{~K}$ since the axial velocity in the $80 \%$ flame varies between $0.35-2.5 \mathrm{~m} / \mathrm{s}$. In this case, the slower axial velocity increases the relative magnitude of the thermophoretic velocity and $\delta$ increases to $\sim 30 \mu \mathrm{m}$. Thus, the local flow velocity can have a significant impact on $\delta$ and needs to be considered at each measurement location. In addition, the flux of particles that reach the grid surface decreases as the TEM grid is increasingly recessed into the probe as seen in the different particle streak widths between the center and right images in Fig. 4. This is another method, in addition to the sample time, by which the percent coverage of aggregates on the TEM grid can be adjusted. The $254 \mu \mathrm{m}$ offset condition was used in this work in order to minimize the probed sample volume. The simulations also suggest that changes in aggregate morphology along the axial direction of the TEM grid may not represent axial gradients in the flow since aggregates at larger $\delta$ reach the top of the grid and aggregates at smaller $\delta$ reach the bottom. An additional solution was computed where the uniform temperature and flow velocities were replaced with radial profiles taken from computational solutions of the $80 \%$ flame [10]. Although still an approximation to the true flow, $\delta$ did not change significantly compared to the corresponding uniform flow condition.

The sample times listed in Section 3.1 were chosen to minimize time spent in the flame while still achieving 5-10\% grid coverage. The simulations suggest that longer exposures capture particles that were initially further upstream than particles acquired during a shorter exposure. For example, if the axial gas phase velocity is representative of the velocity of soot particles throughout their evolution in the flame, then any sample time longer than $\sim 37 \mathrm{~ms}[10]$ at $5 \mathrm{~cm} \mathrm{HAB}$ in the $80 \%$ flame will capture aggregates comprised of carbon from fuel molecules that had not left the fuel tube at the time of probe insertion. Thus, the temperature-time history of particles approaching the thermal boundary layer at different times of probe exposure must be the same for the axial extent of sampled particle streaks to not affect the results.

However, it remains to show that the upstream flame is unperturbed and the conditions are in fact the same. A high-speed video is included in the supplementary material showing the probe being inserted directly into the flame. There is an initial shifting of the flame away from the probe as the sampler is inserted. The flame then returns to its original position and the sample tongue lies within the flame while the upstream portion of the flame is not significantly perturbed. However, as would be expected, the region of the flame downstream of the probe is significantly altered. Flame visualization is not enough information to make a conclusion regarding the effect that sample time has on particle morphology given that the upstream conditions may be perturbed. A simple test was performed by sampling the centerline at $5 \mathrm{~cm} \mathrm{HAB}$ in the 
Yale burner with 50 and $110 \mathrm{~ms}$ exposures. As in Ref. [26], no difference in primary particle diameter was observed to within experimental error. However, differences have been observed (Ref. [44]) in similar flames and a rigorous study is needed to examine the effect of sample time on aggregate morphology.

Fig. 5. End-view illustration of the sampler cross section at the positions used to sample the flame centerline and wing.

Figure 5 illustrates how information from the sample simulations was utilized to extract soot particles from the coflow flames. The yellow denotes the central sooting region of the flame and the orange denotes the flame wings. Dashed lines indicate the radial sample location and the solid lines with an arrow denote the path of a sampled aggregate. The gray boxes represent an end view of a cross section of the sample probe and are included to show the orientation of the probe with respect to the flame. The front face of the sample probe was radially offset from the desired sample location by a distance $\delta$. The centerline samples (see Section 4.2) were taken with $\delta \sim 500 \mu \mathrm{m}$. This value was based on an erroneous assumption of an axial velocity much lower than we believe exists in this flame. However, the results are acceptable due to the relatively uniform soot properties along the centerline and the added distance needed to account for radial probe vibration. Delta along the wing was determined by starting at a radial location where no visible soot deposited on the sample probe. The probe was then moved in $50 \mu \mathrm{m}$ increments until soot visibly deposited on the probe, at which point a sample was taken at the corresponding $\delta$ with a clean TEM grid. Delta at 2, 3.5, and $5 \mathrm{~cm} \mathrm{HAB}$ was found to be 700,600 , and $600 \mu \mathrm{m}$ from the location of peak soot concentration, which occurred at radial locations of $3.1,2.8$, and $2.3 \mathrm{~mm}$, respectively. The agreement between these values and the sampling simulations is fair when considering the added radial motion of the probe due to vibration and the wing thickness. Since only the probe's thermal boundary layer enters the flame, sampling the wing in this manner is less invasive than traditional methods where the probe is placed directly into the desired location.

\subsection{Analysis}

Soot aggregates were collected on 200 mesh copper grids coated with a $15-25 \mathrm{~nm}$ film of pure carbon (Ted Pella Prod. \# 01840) and analyzed on a 200 kV FEI Tecnai Osiris TEM. Magnification was set to $4500 \mathrm{x}$ and $\sim 60$ images were acquired for calculation of $N$ and $R_{g}$ in order to maintain sufficient spatial resolution while achieving an adequate aggregate density for a statistically significant data set. For images used to calculate the distribution of primary particle diameters, the magnification was set to 17500x and 25 images were acquired at each location in order to resolve the range of monomer sizes. In all of the subsequent analysis, aggregates with less than five primary particles were removed from the data set [45]. This is due to the fact that for small $N$, Eq. (1) does not hold. A length scale bar in each image was used to calculate the number of pixels per nanometer. The accuracy of the length scale bar was confirmed by comparison to a $500 \mathrm{~nm}$ diffraction grating (Ted Pella Prod. \# 673) at each magnification.

TEM images of soot particles produce two-dimensional projections of each aggregate. The projected morphology is related to the three-dimensional aggregate morphology through a statistical powerlaw scaling equation. The relation is similar to Eq. (1), except that the radius of gyration is replaced by a new length scale $(L W)^{1 / 2}$, where $L$ and $W$ are the long and short sides of the minimum bounding rectangle of an aggregate [31]. A new fractal prefactor $\left(k_{L W}\right)$ is needed to equate the power-law relationship to the number of primary particles in the aggregate.

$$
N=k_{L W}\left(\frac{2 \sqrt{L W}}{d_{p}}\right)^{D_{f}}
$$

It then follows from Eq. (1) that the radius of gyration is given by the following equation:

$$
R_{g}=\frac{\sqrt{L W}}{\beta}, \quad \beta=\left(\frac{k_{0}}{k_{L W}}\right)^{1 / D_{f}}
$$


A value of $\beta=2.34$ is often assumed based on the work of Köylü et al. [46]. For a single aggregate, the parameter $\beta$ is a strong function of $D_{f}$ and a weak function of $N$ [31]. However, the equations and constants used here are statistical in nature and were developed for use with a large set of aggregates. A similar relation is then used to calculate the number of primary particles per aggregate, since Eq. (7) contains three unknowns in $N, k_{L W}$, and $D_{f}$. This is shown in Eq. (9), where $A_{a}$ is the projected area of the aggregate and $A_{p}$ is the projected area of a primary particle. The empirical parameters used here are $\alpha=1.155$ and $k_{a}=1.095$ [46].

$$
N=k_{a}\left(\frac{A_{a}}{A_{p}}\right)^{\alpha}
$$

Although the RDG-FA theory represents primary particles as being in point contact, this is not the case for flame generated soot aggregates (see Fig. 7) and is one of the factors that limits the RDG-FA theory to $10 \%$ accuracy [15]. The parameters $\alpha$ and $k_{a}$ were derived from stereo-pair images of sampled soot aggregates and therefore empirically consider particle overlap. The parameter $\beta=2.34$ was derived from simulated soot aggregates $\left(D_{f}=1.7, N=100-1000\right)$ in point contact. However, Brasil et al. [47] demonstrated a weak dependence in Eq. (9) on the degree of primary particle overlap using the length scale $L$. If similar behavior holds for the length scale $\sqrt{ } \mathrm{LW}$, a significant error is not expected.

Post-processing of the raw TEM images was done in MATLAB. For calculation of $N$ and $R_{g}$, the images were binned $2 \times 2$ and a Canny edge detection algorithm was used to segment aggregates in the image. This method was efficient at outlining aggregates in the high-contrast low-resolution (4500x) images. However, the technique requires the user to select and zero-out background regions in the image and within each aggregate to create a binary image. A minimum-bounding rectangle was then fit to each aggregate to determine $L$ and $W$, and a Hough transformation was used to calculate the diameter of aggregate monomers [48]. The mean primary particle diameter of each aggregate was used to calculate $A_{p}$ in Eq. (9). The Hough transform decreased the data processing time compared to a manual measurement, although all of the detected primary particles required user screening to ensure proper selection. Improper selection increases as the image contrast decreases, which typically occurs when the image resolution is increased. At each sample location $>350$ primary particle diameters were measured.

In order to compare the optically derived effective radius of gyration with the ex situ sampling results, the same parameter must be derived. The effective soot radius of gyration was defined in Eq. (3) and is rewritten in Eq. (10) after substituting an absolute number density $\left(N^{*}\right)$ multiplied by the probability density function of $N, p(N)$, for $n(N)$.

$$
R_{g, e f f}=\frac{\int N^{2} R_{g}^{2}(N) N^{*} p(N) d N}{\int N^{2} N^{*} p(N) d N} \approx \frac{\sum_{N=5}^{\infty} N^{2} R_{g}^{2}(N) p(N)}{\sum_{N=5}^{\infty} N^{2} p(N)}
$$

The constant $N^{*}$ in both integrands cancel and the remaining terms in Eq. (10) are determined from TEM analysis of the thermophoretically sampled aggregates. In order to substitute $N^{*} p(N)$ for $n(N)$, the thermophoretic velocity must be the same for all particles in the flow as discussed in Section 3.2. In addition, all particles are assumed to adhere to the TEM grid with equal efficiency.

\section{Results and discussion}

\subsection{Light Scattering Results}

Figure 6 contains the new high-resolution maps of $R_{g, e f f}$ and $R^{2}$ (linear fit quality) in the $80 \%$ flame along with a comparison to the previously published results [5]. The data demonstrates improved spatial resolution in addition to a more robust linear fitting. Evolution of soot aggregates along the wings is now apparent in addition to growth along the centerline. This was achieved by minimizing the blurring of data obtained at oblique angles and by using greater magnification in the collection optics and a larger detector. The previous data mapped a slightly larger percentage of the flame due to higher laser fluence and a larger probe volume. Although the two profiles compare well, the new data has moderately lower values along the centerline due to over-smoothing in the previous analysis. Results for the $40 \%$ and $60 \%$ flames are available as supplementary material. 
Fig. 6. New high-resolution map of $R_{g, e f f}$ (right center) and the corresponding $\mathrm{R}^{2}$ map (right) compared to a previous measurement of $R_{g, e f f}$ (left) and the corresponding $\mathrm{R}^{2}$ map (left center) [5].

\subsection{Primary Particle Diameter}

In order validate our method of measuring primary particle diameter and to demonstrate that the sampling process outlined in Section 3.2 is capable of achieving sufficient radial resolution to capture the predicted change in aggregate morphology between the flame wing and centerline, sampling was performed in the extensively-studied Santoro burner (flow condition 1 (NS)) [49]. Previous measurements using TiRe-LII in the Santoro and Yale burners indicate that primary particle diameter is larger and more polydisperse along the wings compared to the centerline [7]. This is observed in the discrete $p d f s$ of primary particle diameter shown on the left in Fig. 7. The monomers were sized from TEM images of soot aggregates taken along the centerline and wing (Fig. 7, right) of the Santoro burner at $5 \mathrm{~cm} \mathrm{HAB}$. The polydispersity and maximum size both increase in the wing compared to the centerline. A mean primary particle diameter of $30.5 \mathrm{~nm}$ was measured along the centerline of the Santoro burner, which agrees well with previous measurements (29.3 nm [50], $35 \pm 3 \mathrm{~nm}$ [26], $31 \mathrm{~nm}$ [51], $33.3 \pm 3.2$ [52], and $32 \mathrm{~nm}$ [53]) and confirms the accuracy of our application of the Hough transformation to determine primary particle diameter. In addition, the sampling process is seen to have sufficient spatial resolution to capture the morphology differences between the flame centerline and wing. Lognormal distributions fit to the TEM data and those from the TiRe-LII measurement are contained in the supplementary material.

Fig. 7. Discrete probability density functions of primary particle diameter at $5 \mathrm{~cm}$ HAB in the Santoro burner operating under condition 1 (NS) (left) and a raw TEM image of large primary particle diameter aggregates used to size monomers in the flame wing (right). The length scale bar in the TEM image is $100 \mathrm{~nm}$.

For the $80 \%$ flame stabilized on the Yale burner, six sampling locations were selected: three along the wing and three along the centerline. Centerline samples were taken at 5, 6, and $7 \mathrm{~cm} \mathrm{HAB}$ while wing samples were taken at 2, 3.5, and $5 \mathrm{~cm}$ HAB (see Fig. 9 in Section 4.3). Discrete $p d f s$ of primary particle diameter are shown on the left in Fig. 8, where the top and bottom rows contain centerline and wing data, respectively. The arithmetic mean of the distribution is listed on each plot and a vertical dashed line represents its location. The increase in maximum primary particle diameter and polydispersity that was observed in the wing compared to the centerline of the Santoro burner is also observed in the $80 \%$ flame at $5 \mathrm{~cm}$ HAB. This is consistent with the TiRe-LII measurement in the $80 \%$ flame and confirms that the sample probe's spatial resolution is sufficient to differentiate between centerline and wing morphology in the Yale burner, which features a significantly smaller fuel tube than the Santoro burner [7]. Lognormal fittings to the TEM derived primary particle data at each sample location are contained in the supplementary material.

Fig. 8. Discrete probability density functions of primary particle diameter at the six measurement locations in the Yale burner $(80 \%)$.

The centerline $p d f s$ of primary particle diameter are relatively uniform, with mean values that are constant to within the measurement uncertainty. The $p d f s$ along the wings are not as uniform. Samples at 3.5 and $5 \mathrm{~cm}$ HAB have similar mean values and polydispersity. However, the $2 \mathrm{~cm}$ HAB sample is less polydisperse and has a smaller mean value that is closer to that of the centerline distributions. We also note that the change in polydispersity results from a significant increase in the probability of larger primary particle diameters. The probability of finding a monomer with diameter $\geq 35 \mathrm{~nm}$ is $0.0085,0.375$, and 0.351 for the $2,3.5$, and $5 \mathrm{~cm}$ HAB samples, respectively. Therefore, the increase in polydispersity and maximum primary particle diameter along the wing compared to the centerline occurs between $\sim 2$ and $\sim 3.5 \mathrm{~cm} \mathrm{HAB}$ in the $80 \%$ flame. Previous computational results for the $80 \%$ flame suggest that acetylene is present along the wings between these two sample locations, which is considered the primary surface growth species [54]. Thus, once aggregates are formed along the wings, as they are at $2 \mathrm{~cm} \mathrm{HAB}$, further 
surface growth is possible due to high temperature and the presence of acetylene. While temperature is also high along the wing between 3.5 and $5 \mathrm{~cm} \mathrm{HAB}$, computations indicate that the acetylene concentration is negligible, which is consistent with our observation of no further growth in primary particle diameter.

Deactivation of the particle surface could also reduce the rate of particle surface growth [54]. Therefore, the increase in maximum primary particle diameter and polydispersity along the wing is consistent with our knowledge of particle surface growth. Acetylene is present along the centerline but at relatively lower temperatures before aggregates are formed. Therefore, primary particle surface growth is negligible and the diameters along the centerline are comparatively uniform.

\subsection{Aggregate size distributions}

The sample locations, along with TEM images of aggregates collected at each location (4500x), are shown in Fig. 9. In order to avoid overlap of aggregates on the TEM grid, soot coverage was kept below $15 \%$ on all images. Table 1 contains the average percent coverage at each measurement location in addition to the number of aggregates used in the following analysis. The median number of monomers per aggregate $\left(N_{m e d}\right)$ and the geometric standard deviation $\left(\sigma_{g}\right)$ are also listed in Table 1 for each sample location and compare well with previous measurements in ethylene flames $[19,55]$.

Table 1. Morphology and sampling information at each location in the $80 \%$ flame.

\begin{tabular}{lllllll}
\hline & Wing Data & \multicolumn{5}{l}{ Centerline Data } \\
\hline HAB & $2 \mathrm{~cm}$ & $3.5 \mathrm{~cm}$ & $5 \mathrm{~cm}$ & $5 \mathrm{~cm}$ & $6 \mathrm{~cm}$ & $7 \mathrm{~cm}$ \\
\hline $\begin{array}{l}\text { Average } \\
\text { Percent } \\
\text { Coverage }\end{array}$ & 5.1 & 4.8 & 6.1 & 9.3 & 6.3 & 9.6 \\
\hline $\begin{array}{l}\text { Number of } \\
\text { Aggregates }\end{array}$ & 3351 & 1385 & 1786 & 1840 & 1260 & 1741 \\
\hline $\boldsymbol{N}_{\text {med }}$ & 14 & 22 & 36 & 47 & 52 & 71 \\
\hline$\sigma_{g}$ & 2.5 & 2.7 & 2.9 & 2.8 & 3.2 & 2.9 \\
\hline $\begin{array}{l}\text { Percent } \\
\text { Difference } \\
\text { in R, }\end{array}$ & 5.8 & 6.8 & 4.6 & 27 & 11 & 3.5 \\
$\begin{array}{l}\text { TEM vs. } \\
\text { 2D-MALS }\end{array}$ & & & & & & \\
\hline
\end{tabular}

Fig. 9. Raw TEM images at the six sample locations illustrated on an Abel-inverted profile of soot emission in the $80 \%$ flame. The length scale bar in the TEM images is $500 \mathrm{~nm}$.

The left column in Fig. 10 plots a cross section of the in situ light scattering measurement of $R_{g, e f f}$ along with a point measurement derived from TEM analysis. The two methods compare very well despite the different diagnostic approaches, with a maximum difference of $27 \%$ occurring at $5 \mathrm{~cm} \mathrm{HAB}$. The agreement becomes progressively better as HAB is increased, and the percent difference between each measurement is listed in the bottom row of Table 1 . The maximum difference can be explained by considering contamination of the centerline sample as it is inserted and extracted, inevitably capturing some aggregates from the flame wing. This effect is maximum at $5 \mathrm{~cm} \mathrm{HAB}$ due to the peak $R_{g, \text { eff }}$ values in the flame occurring in the wing at approximately the same height. As HAB is increased, this effect is reduced as $R_{g \text {,eff }}$ in the wing becomes progressively smaller until $7 \mathrm{~cm} \mathrm{HAB}$ where there is no contribution from the wing. Contamination from large wing aggregates biases the centerline sample toward larger $R_{g, e f f}$ due to a sensitivity to small increases in the probability of large $R_{g}$. Some research has utilized a shield that exposes the grid only at the sample location in order to avoid contamination of the TEM grid during insertion and extraction $[56,57]$. However, the sample probe and shield are stated to have a combined thickness of $6 \mathrm{~mm}$. This length is larger than the maximum width of the coflow flames utilized in this study and would not yield the necessary spatial resolution due to an increased perturbation to the flow field.

The discrete $p d f \mathrm{~s}$ of $R_{g}$ (center) and $N$ (right) sampled along the centerline shown in Fig. 10 are not 
plotted on a log scale, as is commonly done to resolve small probabilities, in order to more clearly show changes in the distribution shape between sample points. The center column shows $p\left(R_{g}\right)$ at the three sample locations, which is observed to shift to a larger mean value with increasing HAB. It is expected that once mature aggregates are formed at the $5 \mathrm{~cm} \mathrm{HAB}$ location, their size would increase with increasing HAB due to growth by diffusion-limited aggregation. The same trend is apparent in $p(N)$ shown in the right column of Fig. 10. Small aggregates $(N<100)$ dominate the percent of occurrence at each measurement location. However, the probability of larger aggregates increases with increased residence time.

Fig. 10. Centerline comparison of $R_{g, e f f}$ determined by 2D-MALS and TEM analysis (left) along with discrete probability distributions for $R_{g}$ (center) and $N$ (right).

Figure 11 is analogous to Fig. 10 and contains samples taken from the flame wing. The agreement between MALS and TEM for $R_{g, e f f}$ is better than along the centerline, with a maximum difference of $<7 \%$ at the $3.5 \mathrm{~cm} \mathrm{HAB} \mathrm{location.} \mathrm{The} \mathrm{growth} \mathrm{of} \mathrm{aggregates} \mathrm{is} \mathrm{apparent} \mathrm{as} \mathrm{the} \mathrm{distributions} \mathrm{widen} \mathrm{with}$ increasing height above burner. Although similar, the wing distributions are not as wide as along the centerline and have comparatively larger probabilities for small aggregates $(N<100)$.

As seen in the six comparative measurements, 2D-MALS accurately measured $R_{g, e f f}$ over a range of $p d f$ widths and mean values. The lower bound for which $\mathrm{R}^{2}$ values above 0.9 could be reliably obtained was $\sim 50 \mathrm{~nm}$ and the maximum $R_{g, e f f}$ in the $80 \%$ flame was $\sim 235 \mathrm{~nm}$.

2D-MALS can qualitatively determine the relative change in aggregate size when particle morphology and probability distributions are not significantly different, as is the case when we consider data only from the centerline or only from the wing. However, when centerline and wing data are compared, the ability to measure aggregate "size" is complicated by differences in morphology resulting from different temperature-time histories. Consider the measurement of $R_{g, e f f}$ at $3.5 \mathrm{~cm} \mathrm{HAB}$ in the wing and $6 \mathrm{~cm} \mathrm{HAB}$ along the centerline; both values were optically determined to be $149 \mathrm{~nm}$. However, the difference between the mean $R_{g}$ values at the two locations is $31 \%$, which is due to different primary particle diameters and distribution widths. Consider the probability of finding an aggregate with $R_{g} \geq$ $200 \mathrm{~nm}$; along the wings $p\left(R_{g} \geq 200 \mathrm{~nm}\right) \approx 2.9 \%$ and along the centerline $p\left(R_{g} \geq 200 \mathrm{~nm}\right) \approx 11 \%$. There is an approximate factor of four difference of finding an aggregate in this large size range between the two locations, despite the same measured $R_{g, e f f}$. Therefore, $R_{g, e f f}$ by itself is not an effective measure of size when comparing aggregates with significantly different temperature-time histories.

Fig. 11. Wing comparison of $R_{g, e f f}$ determined by 2D-MALS and TEM analysis (left) along with discrete probability distributions for $R_{g}$ (center) and $N$ (right).

The shape of $p\left(R_{g}\right)$ and $p(N)$ are important when interpreting changes in $R_{g, e f f}$ due to the fact that $R_{g, e f f}$ can be considered as the product of a mean value and a term comprised of distribution moments:

$R_{g, \text { eff }}=\left[\left(\mathrm{M}_{2+2 / \mathrm{Df}} / \mathrm{M}_{2}\right)^{1 / 2} / \mathrm{M}_{1 / \mathrm{Df}}\right] \cdot R_{g, \text { mean }}[21]$. Thus, although $R_{g, \text { eff }}$ is qualitatively able to capture the growth of aggregates along the centerline or wing, additional information is needed to uncouple information about $R_{g, \text { mean }}$ or $p(N)$. Studies have been done to optically determine $p(N)$, although with limited success over a wide range of aggregate sizes and distributions $[17,21,22,55]$. Thus, TEM analysis not only validated the optical measurement but also helped to elucidate the $R_{g, \text { eff }}$ parameter by providing information about $p\left(R_{g}\right)$ and $p(N)$ at strategic locations.

\subsection{Fractal dimension and prefactor}

As part of the TEM analysis, fractal dimension and prefactor were calculated. The fractal dimension and 2D prefactor can be determined from Eq. (7), utilizing a length scale $(L / 2)$ instead of $(L W)^{1 / 2}$, as the slope and y-intercept of a linear least-square fit of $\log (N)$ and $\log \left(L / d_{p}\right)[45,58]$. The statistical relationship developed by Köylü et al. [58] relates the two and three-dimensional prefactors:

$$
\frac{k_{0}}{k_{L}}=\left(\frac{D_{f}+2}{D_{f}}\right)^{D_{f} / 2}
$$


The fractal dimension and prefactor were found to be relatively constant over the sample locations with mean values of $1.69 \pm 0.02$ and $2.30 \pm 0.17$, respectively. The measurements compare well with Ref. [58] in which $D_{f}=1.7 \pm 0.15$ and $k_{0}=2.4 \pm 0.4$.

\section{Conclusion}

Soot particle morphology is important, not only from a health and environmental standpoint, but also with respect to the development of models that seek to capture the in-flame evolution of soot. The particle morphology affects surface growth, oxidation, and agglomeration processes through the particle's surface area and size. The goal of this work is to provide a multidimensional measurement of aggregate effective radius of gyration in the Yale coflow burner that can be used for the development of soot models.

High-resolution maps of $R_{g, \text { eff }}$ in the $40 \%, 60 \%$, and $80 \%$ flames of the Yale coflow burner were obtained using 2D-MALS. The improved resolution was accomplished through changes in experimental design compared to a previous measurement [5]. The imaging configuration was changed to include a larger detector and increased magnification in the collection optics. The beam thickness was minimized and the focal point was placed at the flame wings, where the spatial gradients are largest and most susceptible to blurring.

In order to extend consideration of factors that affect the sampling process beyond probe vibration, a 2D transient analysis of a uniform flow of nitrogen over a cross section of the probe was conducted. A radial length $\delta$ was defined as the distance between the front face of the sample probe and a particle's upstream radial location, which was found to be $\sim-70 \mu \mathrm{m}(1700 \mathrm{~K}$ and $u=2 \mathrm{~m} / \mathrm{s}), \sim 30 \mu \mathrm{m}(1700 \mathrm{~K}$ and $u=$ $1 \mathrm{~m} / \mathrm{s})$ and $\sim 290 \mu \mathrm{m}(1700 \mathrm{~K}$ and $u=0.35 \mathrm{~m} / \mathrm{s})$. The flame wings were sampled by inserting the probe adjacent to the flame (Fig. 5) so that only the probe's thermal boundary layer entered the flame.

Sampling with sufficient radial spatial resolution to differentiate aggregate centerline and wing morphology was demonstrated through comparison to a previous TiRe-LII measurement of primary particle diameter. The optical measurement showed that primary particles along the wing should be more polydisperse with a larger maximum diameter than at the same HAB along the centerline. Larger primary particles and increased polydispersity were observed in the wing compared to the centerline and confirmed the ability of our sampling method to resolve wing against centerline morphology. A mean diameter of $30.5 \mathrm{~nm}$ along the centerline in the Santoro burner was also observed to compare well with previous measurements and confirmed the accuracy of our application of the Hough transform to size primary particles. The increase in polydispersity and maximum primary particle diameter occurring between $\sim 2$ and $3.5 \mathrm{~cm} \mathrm{HAB}$ in the $80 \%$ flame is thought to result from particle surface growth.

Six measurement locations were selected in the $80 \%$ flame from which the $R_{g, \text { eff }}$ parameter was derived from TEM analysis for comparison to the optical measurement. Excellent agreement was found over the entire set of sample locations, with a maximum difference of $27 \%$ occurring along the centerline at $5 \mathrm{~cm}$ HAB. This difference was explained as artificially high due to contamination of the grid as it was inserted and extracted through the flame wing. Agreement along the wing was improved compared to the centerline, with a maximum difference of $<7 \%$ occurring at the $3.5 \mathrm{~cm}$ HAB location.

The effective soot radius of gyration is an interesting parameter from which to study the size of aggregates since it implicitly contains information about $R_{g \text {,mean }}$ and $p(N)$. These parameters are important to fully define a polydisperse distribution of aggregates. For a soot model, the effective radius of gyration could be computed for comparison to 2D-MALS results. However, TEM analysis also benefits the $R_{g, e f f}$ measurement since it provided validation and additional information at strategic locations about the $p d f s$ of $R_{g}$ and $N$. Thus, the relation of the optically derived $R_{g, \text { eff }}$ to the local aggregate size distribution is elucidated through TEM analysis.

The fractal dimension and prefactor were calculated as part of the TEM analysis and found to be approximately constant over the flame. The length scale of $(L / 2)$ produced $D_{f, \text { mean }}=1.69 \pm 0.02$ and $k_{0, \text { mean }}=$ $2.30 \pm 0.17$, which compares well with published values [58]. 


\section{Acknowledgements}

This research was supported by the National Science Foundation under Grant 1403224.

\section{References}

[1] T.R. Barfknecht, Toxicology of Soot, Prog. Energy Combust. Sci., 9 (1983) 199-237.

[2] I.M. Kennedy, The health effects of combustion-generated aerosols, Proc. Combust. Inst., 31 (2007)

2757-2770.

[3] M.G. Flanner, C.S. Zender, J.T. Randerson, P.J. Rasch, Present-day climate forcing and response from black carbon in snow, J. Geophys. Res., 112 (2007).

[4] P.B. Kuhn, B. Ma, B.C. Connelly, M.D. Smooke, M.B. Long, Soot and thin-filament pyrometry using a color digital camera, Proc. Combust. Inst., 33 (2011) 743-750.

[5] B. Ma, M.B. Long, Combined soot optical characterization using 2-D multi-angle light scattering and spectrally resolved line-of-sight attenuation and its implication on soot color-ratio pyrometry, Appl. Phys. B, 117 (2014) 287-303.

[6] N.J. Kempema, M.B. Long, Quantitative Rayleigh thermometry for high background scattering applications with structured laser illumination planar imaging, Appl. Opt., 53 (2014) 6688-6697.

[7] Blair Connelly, Quantitative characterization of steady and time-varying, sooting, laminar diffusion flames using optical techniques, Ph.D. Thesis, Yale University, New Haven, CT, 2009.

http://guilford.eng.yale.edu/bcc thesis.pdf

[8] B. Ma, M.B. Long, Absolute light calibration using S-type thermocouples, Proc. Combust. Inst., 34 (2013) 3531-3539.

[9] B.C. Connelly, M.B. Long, M.D. Smooke, R.J. Hall, M.B. Colket, Computational and experimental investigation of the interaction of soot and NO in coflow diffusion flames, Proc. Combust. Inst., 32 (2009) 777-784.

[10] M.D. Smooke, M.B. Long, B.C. Connelly, M.B. Colket, R.J. Hall, Soot formation in laminar diffusion flames, Combust. Flame, 143 (2005) 613-628.

[11] B.C. Connelly, B.A.V. Bennett, M.D. Smooke, M.B. Long, A paradigm shift in the interaction of experiments and computations in combustion research, Proc. Combust. Inst., 32 (2009) 879-886.

[12] http://www.adelaide.edu.au/cet/isfworkshop/data-sets/laminar/ (09/2015)

[13] M. Kholghy, M. Saffaripour, C. Yip, M.J. Thomson, The evolution of soot morphology in a laminar coflow diffusion flame of a surrogate for Jet A-1, Combust. Flame, 160 (2013) 2119-2130.

[14] Q. Zhang, H. Guo, F. Liu, G.J. Smallwood, M.J. Thomson, Implementation of an advanced fixed sectional aerosol dynamics model with soot aggregate formation in a laminar methane/air coflow diffusion flame, Combust. Theor. Model., 12 (2008) 621-641.

[15] C.M. Sorensen, Light scattering by fractal aggregates: A review, Aerosol Sci Tech, 35 (2001) 648-687. [16] B.M. Crosland, K.A. Thomson, M.R. Johnson, Instantaneous in-flame measurement of soot volume fraction, primary particle diameter, and aggregate radius of gyration via auto-compensating laser-induced incandescence and two-angle elastic light scattering, Appl. Phys. B, 112 (2013) 381-393.

[17] D.R. Snelling, O. Link, K.A. Thomson, G.J. Smallwood, Measurement of soot morphology by integrated LII and elastic light scattering, Appl. Phys. B, 104 (2011) 385-397.

[18] H. Oltmann, J. Reimann, S. Will, Wide-angle light scattering (WALS) for soot aggregate characterization, Combust. Flame, 157 (2010) 516-522.

[19] H. Oltmann, J. Reimann, S. Will, Single-shot measurement of soot aggregate sizes by wide-angle light scattering (WALS), Appl. Phys. B, 106 (2012) 171-183.

[20] S.S. Iyer, T.A. Litzinger, S.-Y. Lee, R.J. Santoro, Determination of soot scattering coefficient from extinction and three-angle scattering in a laminar diffusion flame, Combust. Flame, 149 (2007) 206-216. [21] O. Link, D.R. Snelling, K.A. Thomson, G.J. Smallwood, Development of absolute intensity multiangle light scattering for the determination of polydisperse soot aggregate properties, Proc. Combust. Inst., 33 (2011) 847-854.

[22] D.W. Burr, K.J. Daun, O. Link, K.A. Thomson, G.J. Smallwood, Determination of the soot aggregate size distribution from elastic light scattering through Bayesian inference, J. Quant. Spectrosc. Radiat. Transfer, 112 (2011) 1099-1107.

[23] S. Will, S. Schraml, A. Leipertz, Comprehensive two-dimensional soot diagnostics based on laserinduced incandescence (LII), Symp. (Int.) Combust., 26 (1996) 2277-2284. 
[24] J. Reimann, S.A. Kuhlmann, S. Will, 2D aggregate sizing by combining laser-induced incandescence (LII) and elastic light scattering (ELS), Appl. Phys. B, 96 (2009) 583-592.

[25] S. De Iuliis, S. Maffi, F. Cignoli, G. Zizak, Three-angle scattering/extinction versus TEM measurements on soot in premixed ethylene/air flame, Appl. Phys. B, 102 (2011) 891-903.

[26] R.A. Dobbins, C.M. Megaridis, Morphology of Flame-Generated Soot as Determined by Thermophoretic Sampling, Langmuir, 3 (1987) 254-259.

[27] M. Schenk, S. Lieb, H. Vieker, A. Beyer, A. Golzhauser, H. Wang, K. Kohse-Hoinghaus, Imaging Nanocarbon Materials: Soot Particles in Flames are Not Structurally Homogeneous, Chem. Phys. Chem., 14 (2013) 3248-3254.

[28] J. Lee, I. Altman, M. Choi, Design of thermophoretic probe for precise particle sampling, J. Aerosol. Sci., 39 (2008) 418-431.

[29] http://guilford.eng.yale.edu/yalecoflowflames/ (09/2015)

[30] G. Wang, C.M. Sorensen, Experimental Test of the Rayleigh-Debye-Gans Theory for Light Scattering by Fractal Aggregates, Appl. Opt., 41 (2002) 4645-4651.

[31] M. Wozniak, F.R.A. Onofri, S. Barbosa, J. Yon, J. Mroczka, Comparison of methods to derive morphological parameters of multi-fractal samples of particle aggregates from TEM images, J. Aerosol. Sci., 47 (2012) 12-26.

[32] R.L. Vander Wal, M.Y. Choi, Pulsed laser heating of soot: morphological changes, Carbon, 37 (1999) 231-239.

[33] R.L. Vander Wal, T.M. Ticich, A.B. Stephens, Optical and microscopy investigations of soot structure alterations by laser-induced incandescence, Appl. Phys. B, 67 (1998) 115-123.

[34] G.D. Yoder, P.K. Diwakar, D.W. Hahn, Assessment of soot particle vaporization effects during laserinduced incandescence with time-resolved light scattering, Appl. Opt., 44 (2005) 4211-4219.

[35] P.A.M. Kalt, M.B. Long, OMA2-Image Processing for MAC OS X, 2014. http://www.oma-X.org

[36] J.D. Herdman, B.C. Connelly, M.D. Smooke, M.B. Long, J.H. Miller, A comparison of Raman signatures and laser-induced incandescence with direct numerical simulation of soot growth in nonpremixed ethylene/air flames, Carbon, 49 (2011) 5298-5311.

[37] S.L. Goren, Thermophoresis of Aerosol-Particles in Laminar Boundary-Layer on a Flat-Plate, J. Colloid Interf. Sci., 61 (1977) 77-85.

[38] L. Talbot, R.K. Cheng, R.W. Schefer, D.R. Willis, Thermophoresis of Particles in a Heated BoundaryLayer, J. Fluid. Mech., 101 (1980) 737-758.

[39] D.E. Rosner, D.W. Mackowski, P. Garciaybarra, Size-Insensitivity and Structure-Insensitivity of the Thermophoretic Transport of Aggregated Soot Particles in Gases, Combust. Sci. Technol., 80 (1991) 87101.

[40] P. Garciaybarra, D.E. Rosner, Thermophoretic Properties of Nonspherical Particles and Large Molecules, Aiche. J., 35 (1989) 139-147.

[41] A. Gomez, D.E. Rosner, Thermophoretic Effects on Particles in Counterflow Laminar Diffusion Flames, Combust. Sci. Technol., 89 (1993) 335-362.

[42] M.Y. Choi, G.W. Mulholland, A. Hamins, T. Kashiwagi, Comparisons of the Soot Volume Fraction Using Gravimetric and Light Extinction Techniques, Combust. Flame, 102 (1995) 161-169.

[43] K. Tian, F.S. Liu, K.A. Thomson, D.R. Snelling, G.J. Smallwood, D.S. Wang, Distribution of the number of primary particles of soot aggregates in a nonpremixed laminar fame, Combust. Flame, 138 (2004) 195-198.

[44] E. Cenker, G. Bruneaux, T. Dreier, C. Schulz, Determination of small soot particles in the presence of large ones from time-resolved laser-induced incandescence, Appl. Phys. B, 118 (2015) 169-183.

[45] K. Tian, K.A. Thomson, F.S. Liu, D.R. Snelling, G.J. Smallwood, D.S. Wang, Determination of the morphology of soot aggregates using the relative optical density method for the analysis of TEM images, Combust. Flame, 144 (2006) 782-791.

[46] U.O. Koylu, G.M. Faeth, T.L. Farias, M.G. Carvalho, Fractal and Projected Structure Properties of Soot Aggregates, Combust. Flame, 100 (1995) 621-633.

[47] A.M. Brasil, T.L. Farias, M.G. Carvalho, A recipe for image characterization of fractal-like aggregates, J. Aerosol. Sci., 30 (1999) 1379-1389.

[48] I. Grishin, K. Thomson, F. Migliorini, J.J. Sloan, Application of the Hough transform for the automatic determination of soot aggregate morphology, Appl. Opt., 51 (2012) 610-620.

[49] R.J. Santoro, H.G. Semerjian, R.A. Dobbins, Soot Particle Measurements in Diffusion Flames, Combust. Flame, 51 (1983) 203-218. 
[50] C. Schulz, B.F. Kock, M. Hofmann, H. Michelsen, S. Will, B. Bougie, R. Suntz, G. Smallwood, Laserinduced incandescence: recent trends and current questions, Appl. Phys. B, 83 (2006) 333-354.

[51] U.O. Koylu, C.S. McEnally, D.E. Rosner, L.D. Pfefferle, Simultaneous measurements of soot volume fraction and particle size/microstructure in flames using a thermophoretic sampling technique, Combust. Flame, 110 (1997) 494-507.

[52] R.L. Vander Wal, T.M. Ticich, A.B. Stephens, Can soot primary particle size be determined using laser-induced incandescence?, Combust. Flame, 116 (1999) 291-296.

[53] R. Puri, T.F. Richardson, R.J. Santoro, R.A. Dobbins, Aerosol Dynamic Processes of Soot Aggregates in a Laminar Ethene Diffusion Flame, Combust. Flame, 92 (1993) 320-333.

[54] S.J. Harris, A.M. Weiner, Surface Growth of Soot Particles in Premixed Ethylene Air Flames, Combust. Sci. Technol., 31 (1983) 155-167.

[55] U.O. Koylu, Quantitative analysis of in situ optical diagnostics for inferring particle/aggregate parameters in flames: Implications for soot surface growth and total emissivity, Combust. Flame, 109 (1997) 488-500.

[56] J. Cho, M. Choi, Determination of number density, size and morphology of aggregates in coflow diffusion flames using light scattering and local sampling, J. Aerosol. Sci., 31 (2000) 1077-1095.

[57] M. Choi, J. Cho, J. Lee, H.W. Kim, Measurements of silica aggregate particle growth using light scattering and thermophoretic sampling in a coflow diffusion flame, J. Nanopart. Res., 1 (1999) 169-183. [58] U.O. Koylu, Y.C. Xing, D.E. Rosner, Fractal morphology analysis of combustion-generated aggregates using angular light scattering and electron microscope images, Langmuir, 11 (1995) 4848-4854. 


\begin{tabular}{|c|c|c|c|c|c|c|}
\hline \multirow[b]{2}{*}{ НАВ } & \multicolumn{3}{|c|}{ Wing Data } & \multicolumn{3}{|c|}{ Centerline Data } \\
\hline & $2 \mathrm{~cm}$ & $3.5 \mathrm{~cm}$ & $5 \mathrm{~cm}$ & $5 \mathrm{~cm}$ & $6 \mathrm{~cm}$ & $7 \mathrm{~cm}$ \\
\hline $\begin{array}{l}\text { Average } \\
\text { Percent } \\
\text { Coverage }\end{array}$ & 5.1 & 4.8 & 6.1 & 9.3 & 6.3 & 9.6 \\
\hline $\begin{array}{l}\text { Number of } \\
\text { Aggregates }\end{array}$ & 3351 & 1385 & 1786 & 1840 & 1260 & 1741 \\
\hline$N_{m e d}$ & 14 & 22 & 36 & 47 & 52 & 71 \\
\hline$\sigma_{g}$ & 2.5 & 2.7 & 2.9 & 2.8 & 3.2 & 2.9 \\
\hline $\begin{array}{l}\text { Percent } \\
\text { Difference } \\
\text { in } R_{\mathrm{g}, \text { eff }} \text { for } \\
\text { TEM vS. } \\
\text { 2D-MALS }\end{array}$ & 5.8 & 6.8 & 4.6 & 27 & 11 & 3.5 \\
\hline
\end{tabular}




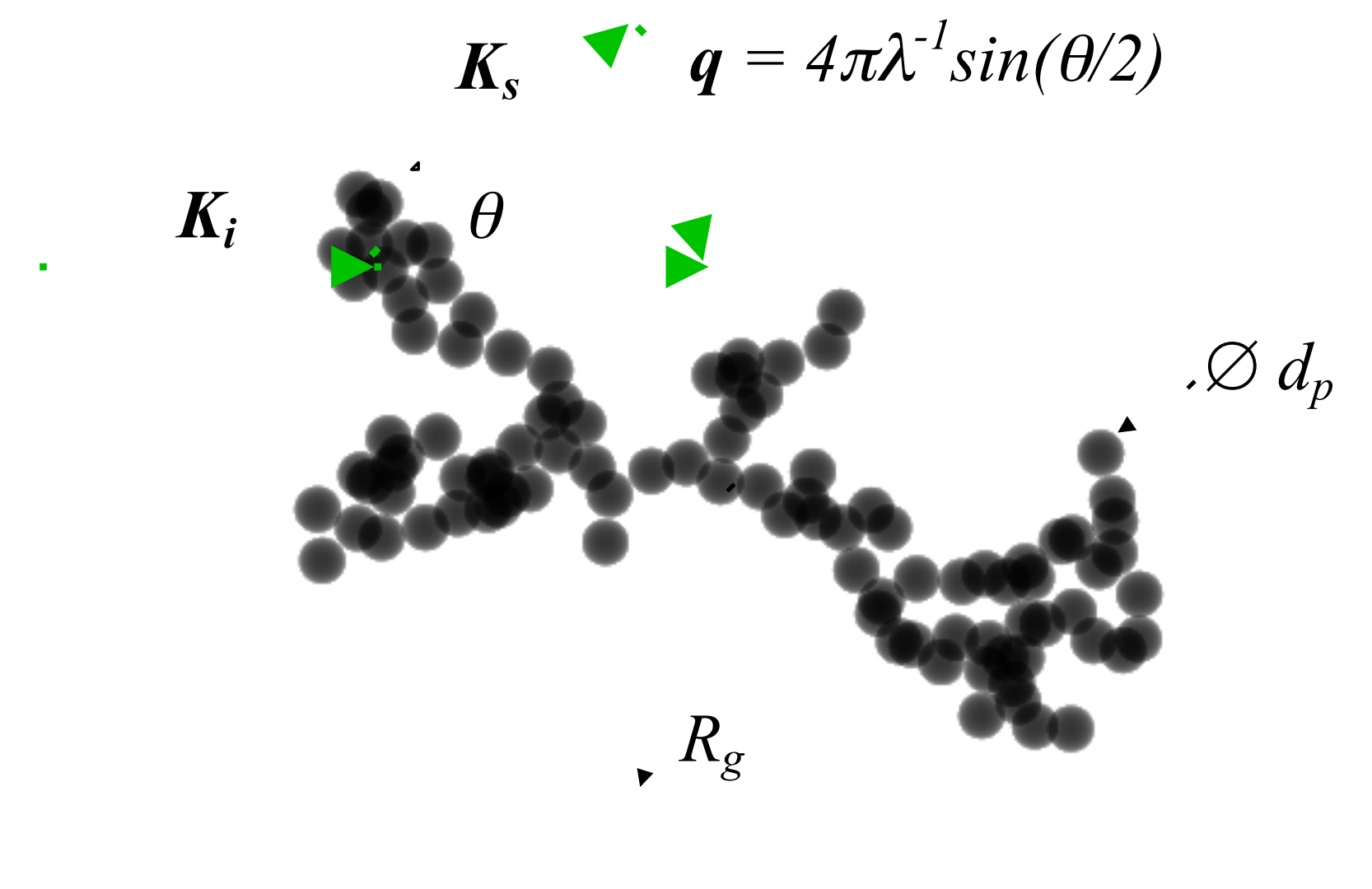

Figure1
\[ K_{s} \nabla q=4 \pi \lambda^{-1} \sin (\theta / 2) \]

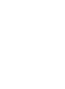

$$
\boldsymbol{K}_{\boldsymbol{s}} \nabla \boldsymbol{q}=4 \pi \lambda^{-1} \sin (\theta / 2)
$$

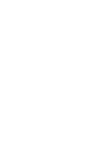

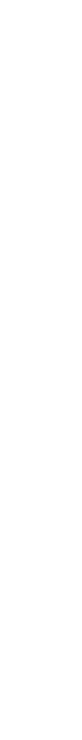




\section{End View Cut Away}

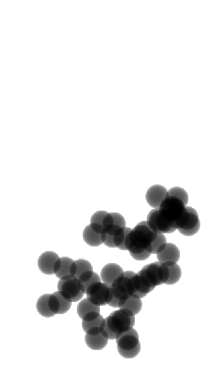

*.

$\triangle$ Axial

- Temperature

\section{Side View}
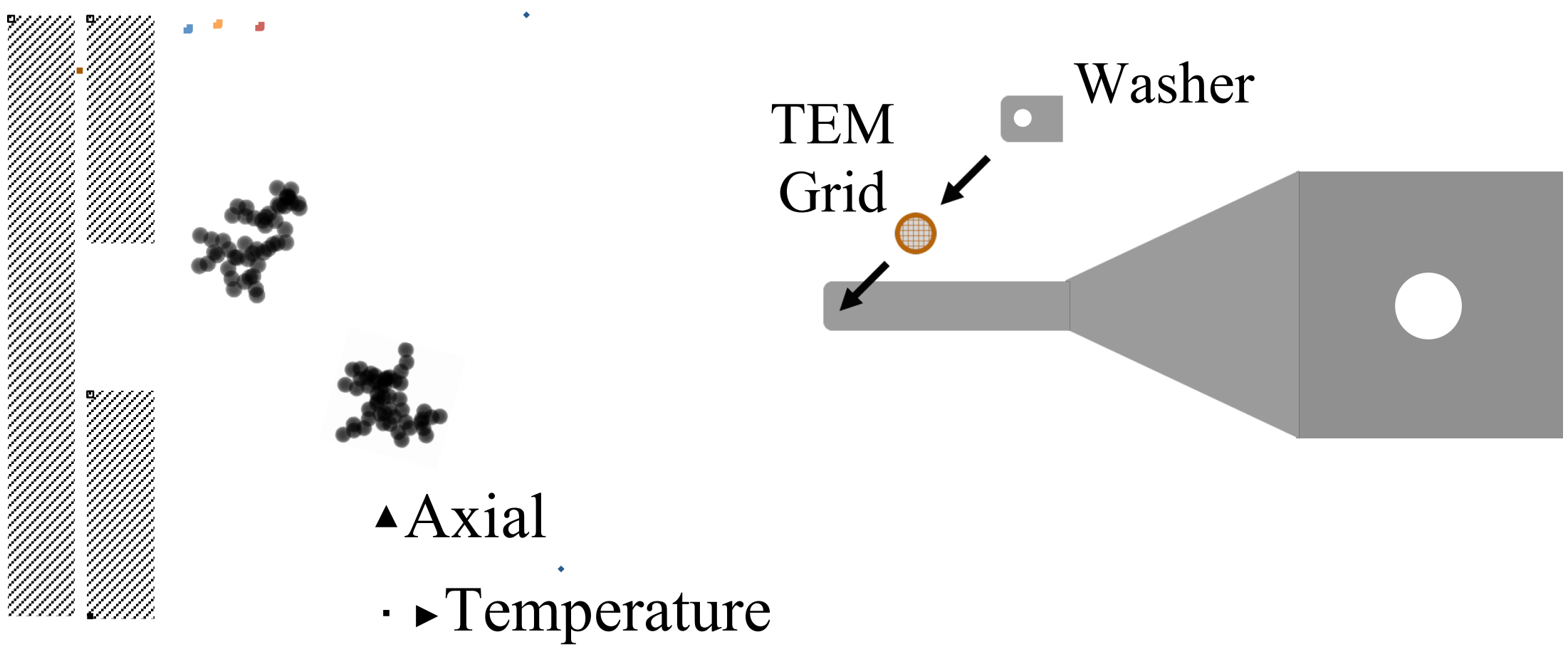

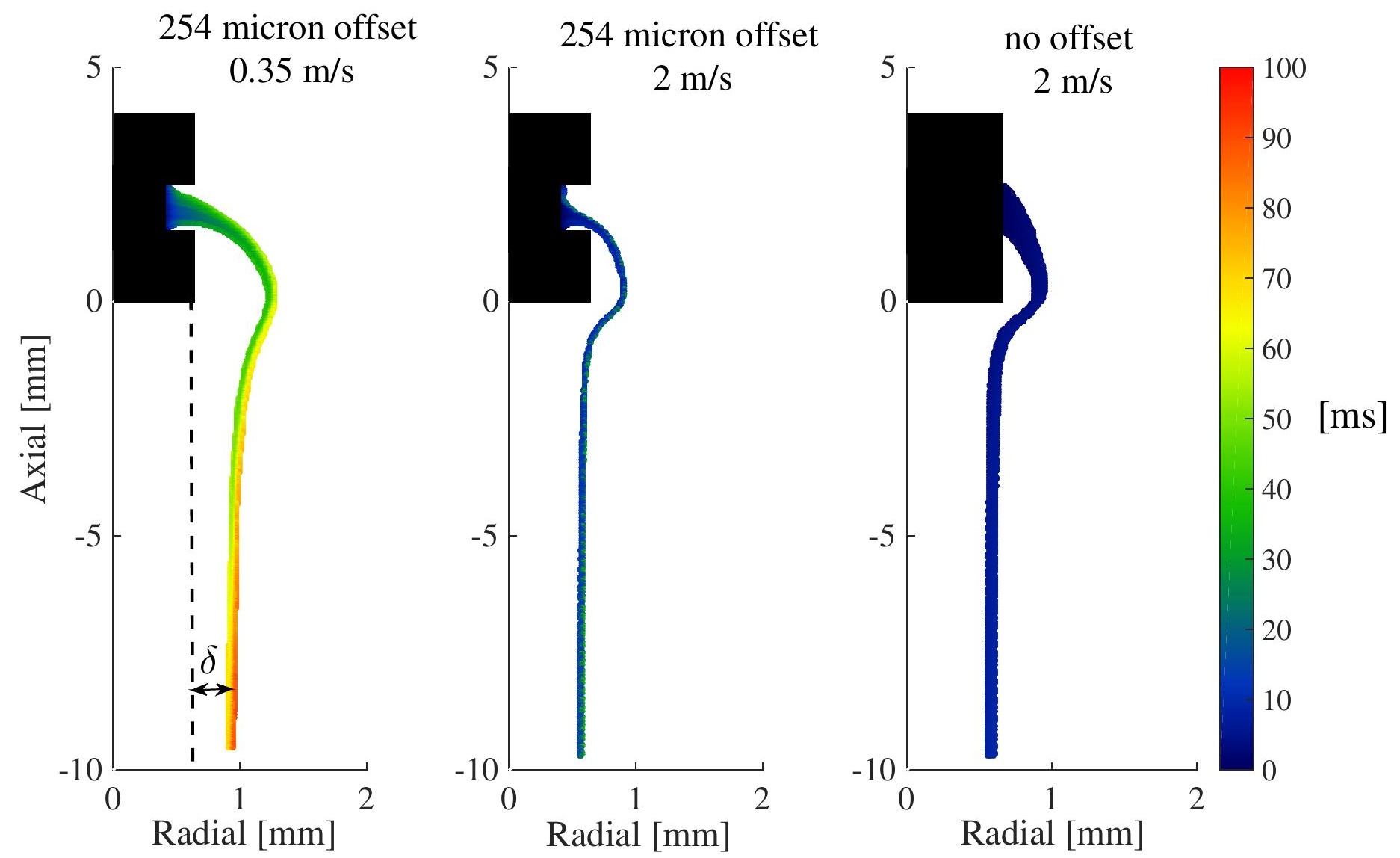


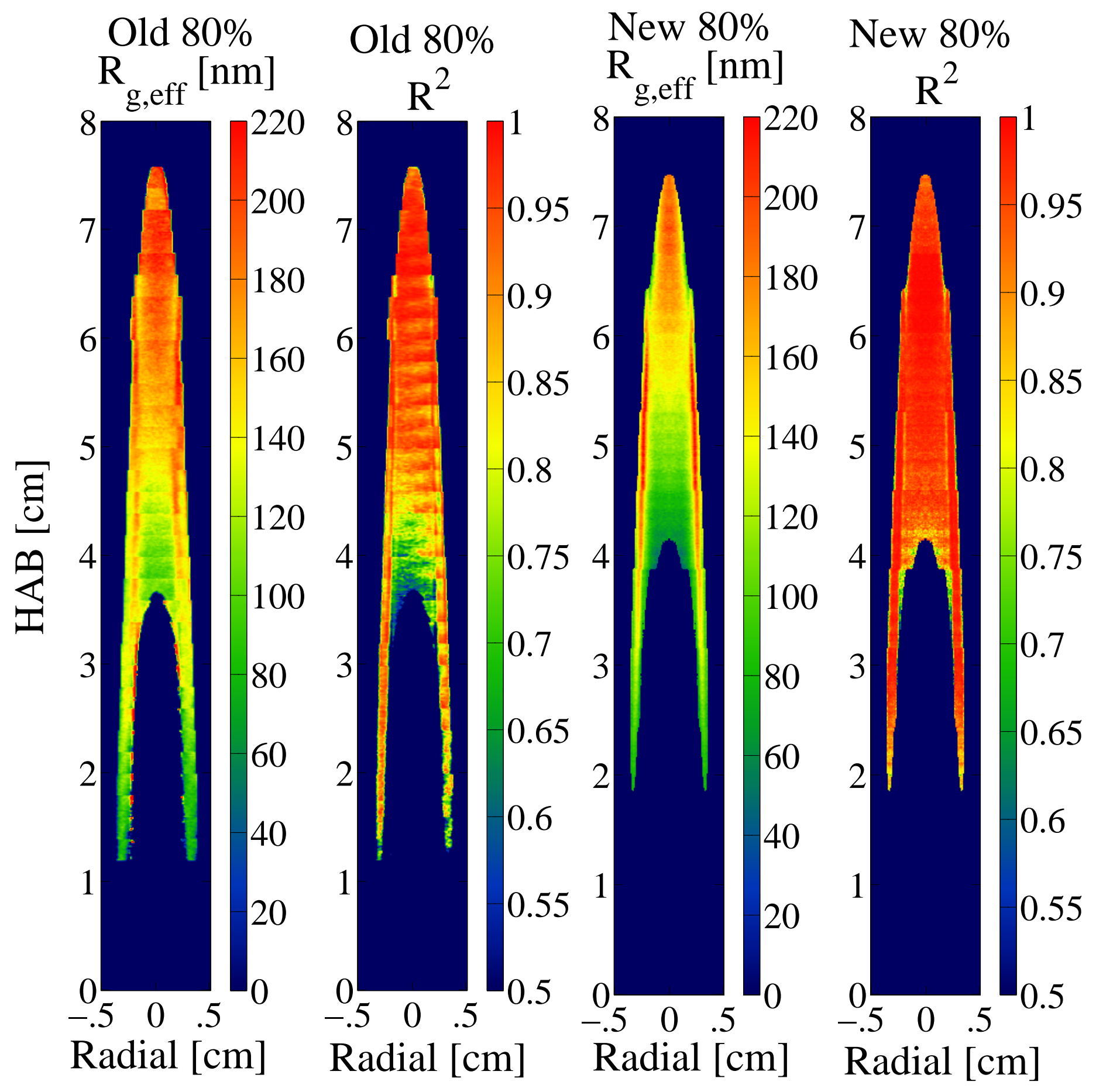



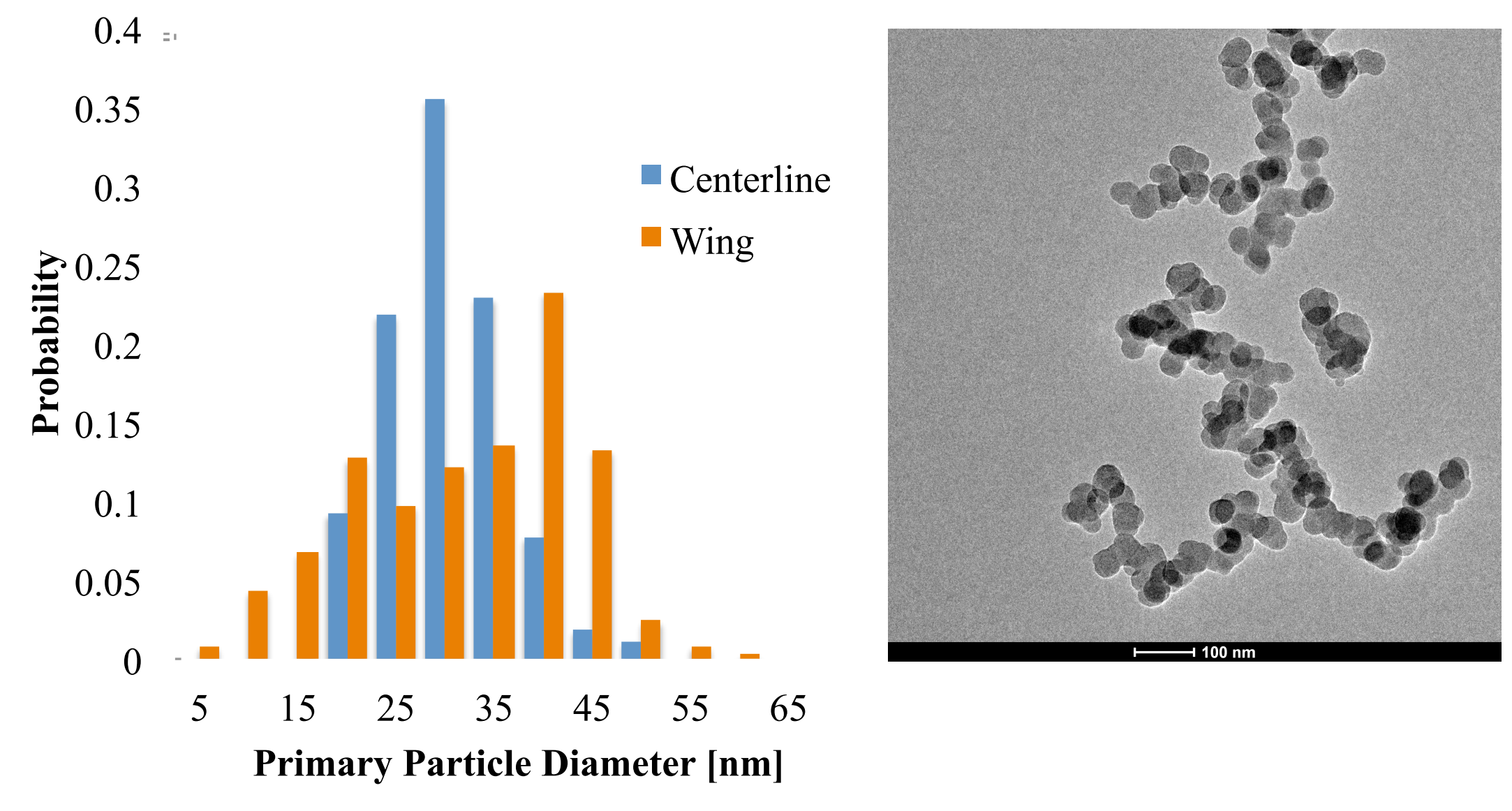

\section{Primary Particle Diameter [nm]}

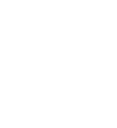

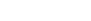




\section{Centerline: $5 \mathrm{~cm} \mathrm{HAB}$}

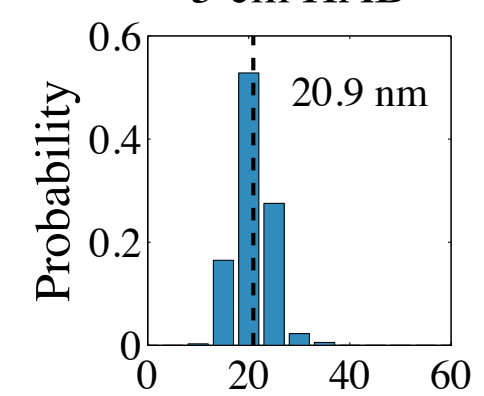

Wing: $\quad 2 \mathrm{~cm} \mathrm{HAB}$

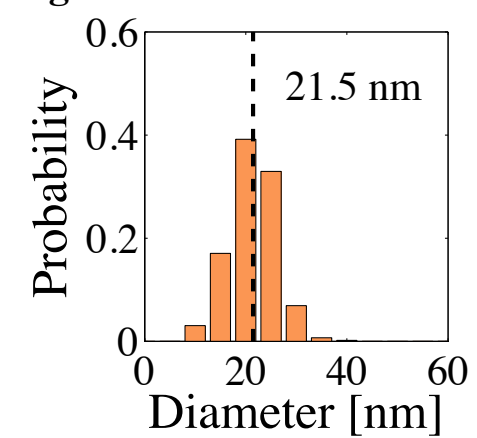

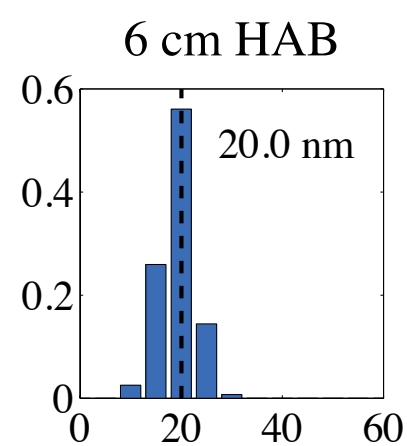
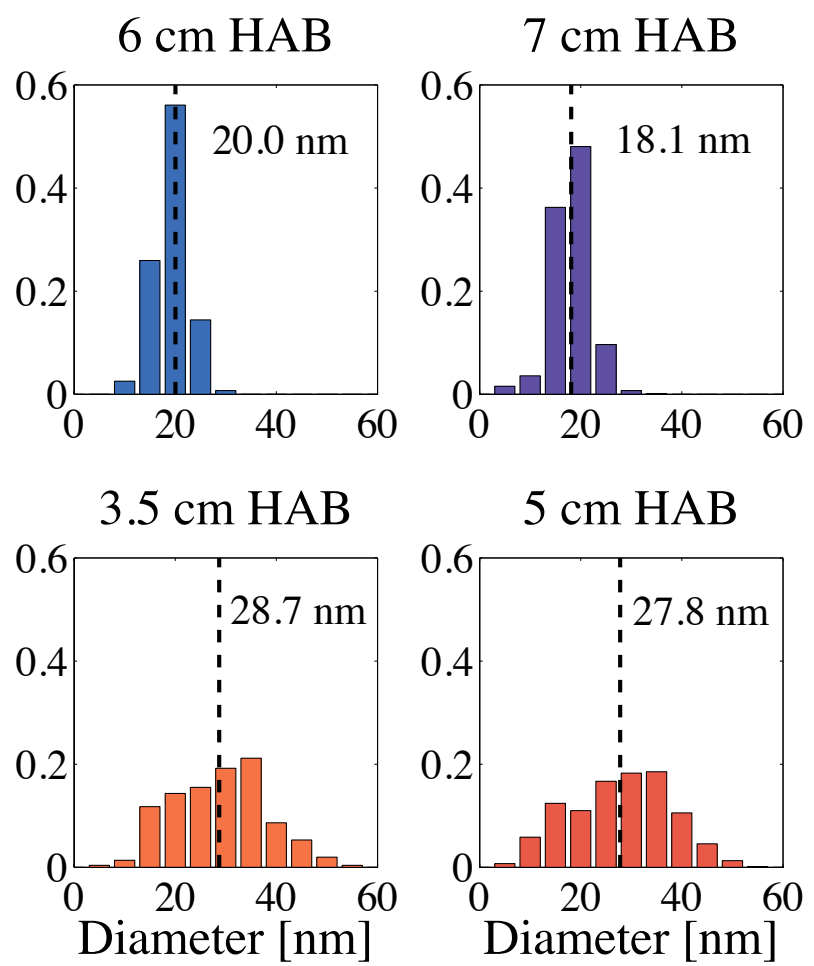
Click here to download Figure: FIG9.pdf

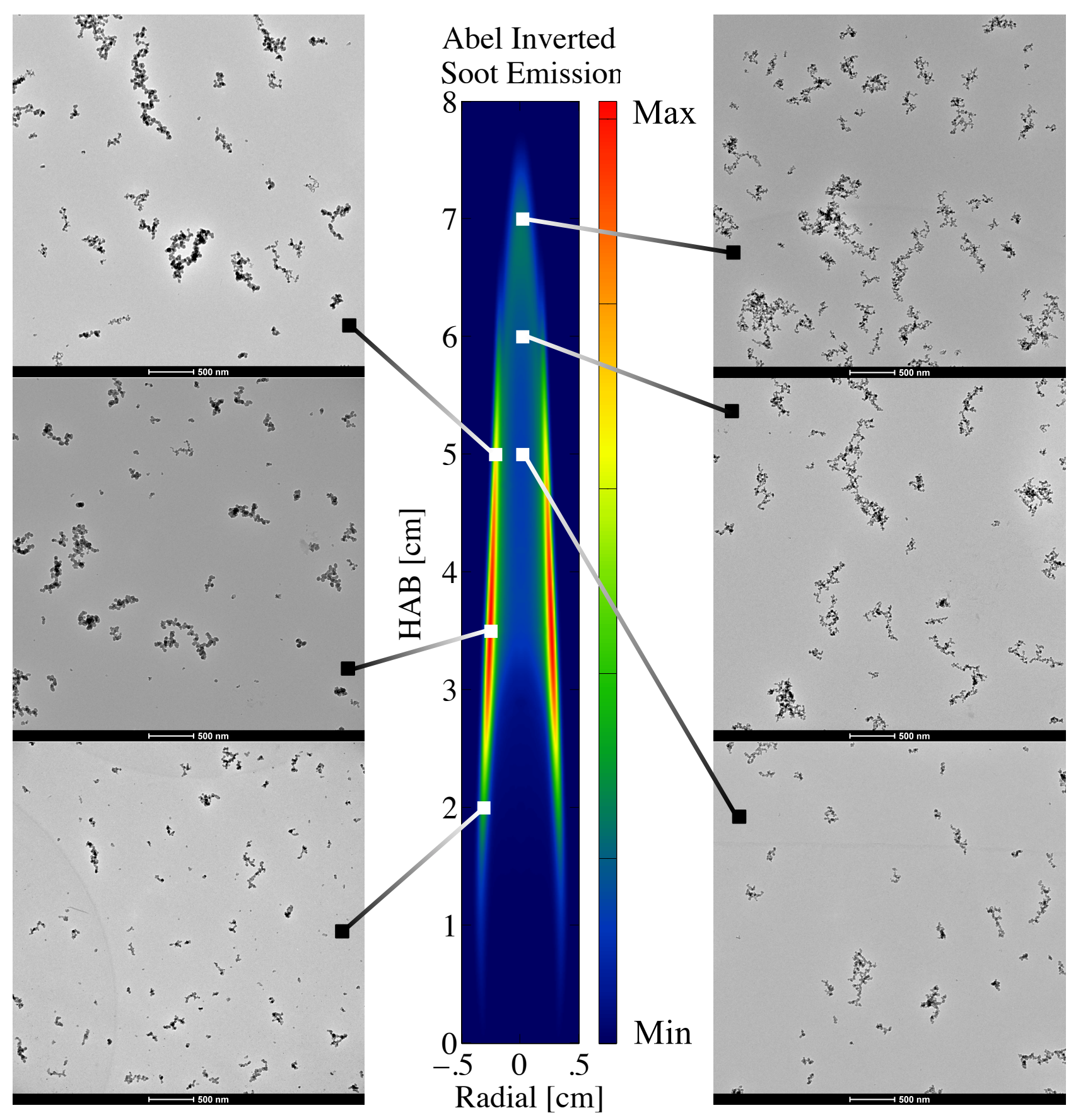



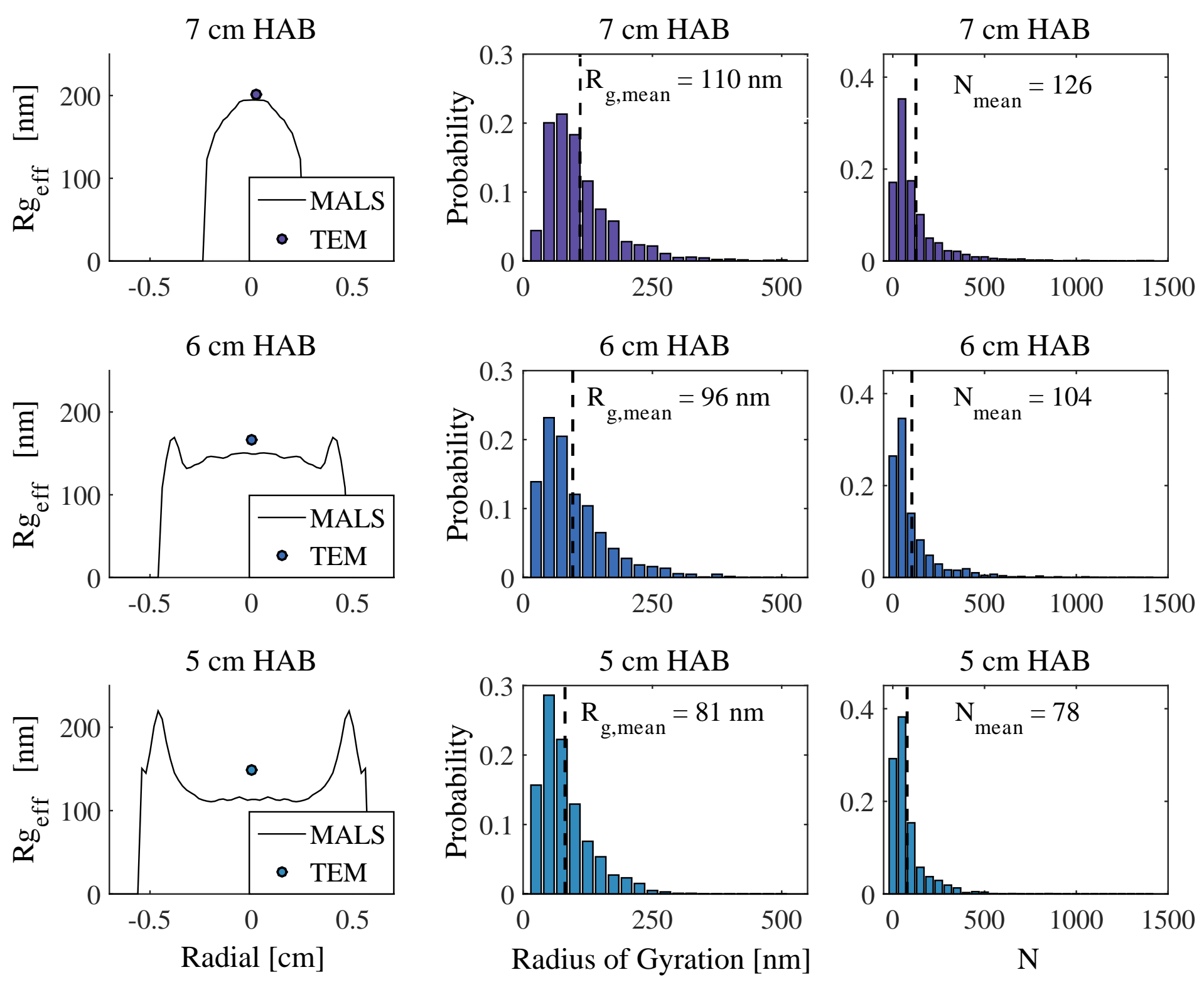

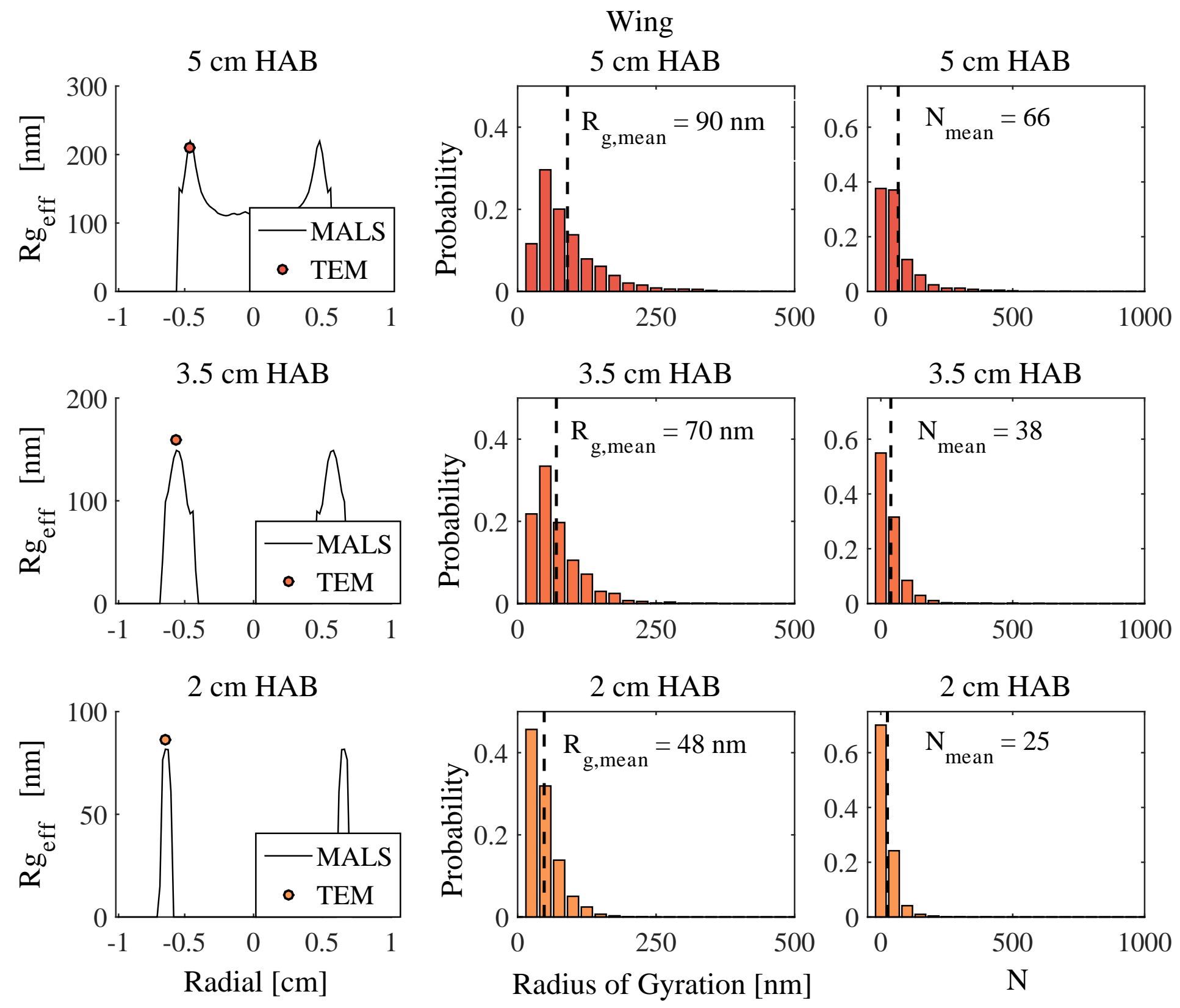